colon appeared normal. The only abnormal finding was an adhesion from the greater omentum to the left end of the transverse colon. All vessels were normal and it did not appear that they had ever been occluded.

The ischaemic colitis syndrome exists in the absence of vascular occlusion, and while it is conceded that arterial thrombosis may follow the taking of oral contraceptives care should be taken before attributing a causative role to these drugs, particularly in this syndrome.-We are, etc.,

H. A. F. Dudley IRWIN FARIS

Department of Surgery,

Victoria, Australia

\section{Rifampicin and Thrombocytopenia}

SIR,-Dr. G. Poole and others (7 August, p. 343) reported the occurrence of thrombocytopenia in patients receiving rifampicin in the dose of $1,200 \mathrm{mg}$ twice weekly.

I have recently seen a patient who developed spontaneous bruising while receiving rifampicin in a dose of $600 \mathrm{mg}$ daily. She had been on rifampicin for about nine months. She was found to have a platelet count of $44,000 / \mathrm{mm}^{3}$ but no other haematological abnormality. Her antituberculosis chemotherapy was stopped and over the course of the next few days the bruising disappeared. One week later her platelet count was $242,000 / \mathrm{mm}^{3}$ and has remained normal since.

By the kind co-operation of Dr. Peter Stradling, of the Hammersmith Hospital, the patient's serum was tested and gave no evidence of rifampicin-dependent antibodies by any of the methods described in the report referred to above.

It is not certain that the thrombocytopenia was due to rifampicin as the patient had also been receiving ethambutol and pyrazinamide, but so far as I am aware these drugs have not been reported to cause platelet abnormalities and it may be that clinicians should keep a watch for this potentially serious side effect in patients receiving daily rifampicin also.-I am, etc., General Hospital
Northampton

\section{G. C. Ferguson}

\section{Hospital Staff Appointments}

SIR,-It does not seem to have occurred to Mr. W. E. Jacobs (14 August, p. 435) that if one is job-hunting one may need to apply for several posts simultaneously, and that the interview for the job one really wants may come after that for one which is inferior. It takes a certain amount of cash in the bank or a lot of confidence to withdraw from the first interview in the hope of success in the later one. It could even be that the job at his hospital isn't quite as attractive as he thinks it is. There is a lot to be said for consultants and hospitals having to provide references by previous holders of the post advertised.

The Hospital Gazetteer is rather less useful than the A.A. hotel guide; what is really needed is a register as candid and hardhitting as a Which? report.
When I was last job-hunting, I drew up forms asking for what $I$ felt was the most relevant information about the job and accommodation offered, which I sent to the hospitals with my applications. This obviously startled many of the recipients, but it did save me some wasted journeys-including the one or two who did not feel it was necessary to reply until the interview. Obviously any consultant or administrator who takes this attitude is unlikely to be a congenial person to work with, and frankly they don't deserve to have any junior staff.

One other point that could be mentioned, which causes considerable resentment, is the "rigged" appointment. Please note I am not complaining about hospitals appointing someone whom they already know; I think it is usually much more satisfactory for all concerned if the person known and liked locally gets the job, and if one has held a post satisfactorily as a locum, then one darn well should get it. What I do think is wrong is to call candidates from all over the country just to put on a show of "fairness;" actually it is very unfair to the other candidates, whose hopes are raised unnecessarily, whose time is wasted, who may miss another interview where they might have been successful, and who invariably end up out of pocket as the subsistence rates paid are completely out of touch with present costs of hotels and restaurants. Furthermore, some regional boards will not pay expenses for visiting the hospitals prior to interview, though this is a sensible precaution (for both sides), particularly where the post is one to be held for more than a few months, and if candidates were encouraged to do this there might be fewer late withdrawals.-I am, etc.,

Eastbourne, Sussex

Paula H. Gosling

SIR,-While agreeing with Mr. W. E. Jacobs (14 August, p. 435) that it is very wrong for hospital junior doctors to accept posts and then turn them down at a later date, I feel the hospitals themselves are partly to blame for the following reasons.

Posts are usually advertised only a few weeks before the job is due to start. So many doctors approaching the end of their contract have no new post to go to. They are then tempted to accept a post they do not like in order to give their family a home. Subsequently, when offered a job they do like they turn the first job down. This applies particularly to foreign doctors with no relatives to impose upon.

Insufficient information about posts is usually given before interview. A candidate may accept the post before he has had sufficient time to consider the disadvantages such as poor accommodation, no postgraduate facilities, poor library, night cover for other specialties, and poor off duty.

Contracts for hospital junior staff are extremely short-a problem faced by no other employee of the N.H.S. Two-year rotating appointments with some thought for the training needs of the young doctor would reduce the turnover of staff and also reduce the difficulties encountered by the hospitals and the doctors.

If any job is continually being turned down by candidates after interview the job itself should be investigated. Better training facilities and conditions of work may produce a suitable doctor.-I am, etc.,

Portsmouth,

A. J. MILLER

Portsmo

\section{Thromboplastin Reference Preparations}

SIR,-The statement by Drs. Rosemary Biggs and D. R. Bangham (21 August, p. 470) represents the culmination of several years study by the Thromboplastin Subcommittee of the International Committee for Haemostasis and Thrombosis, with which I and many others have been associated. It is therefore a landmark in the development of stable international reference preparations for thromboplastin.

It is important, however, to emphasize several points lest there be confusion in British hospitals regarding the implications of their statement as we already have a nationally adopted scheme for anticoagulant control. It should first be mentioned that one of these proposed international reference preparations (Thromboplastin $1(69 / 223)$ plain) is in fact a special batch of material provided from Manchester which had been processed in a similar way to the British Comparative Thromboplastin. It is in fact identical with the B.C.T. for the purposes of anticoagulant control, provided that the proposed reference preparation $(69 / 223)$ remains stable. The properties of the B.C.T. are in all events well established in clinical practice. whereas the other reference reagents are unknown quantities in terms of treatment ranges and could not be used with the same degree of confidence.

The thromboplastin sensitivity ratio advocated in the statement is completely different from our nationally adopted system for reporting prothrombin results using the British Corrected Ratio and the two must be distinguished. The method of obtaining the B.C.R. has been explained in detail in an A.C.P. Broadsheet and elsewhere. ${ }^{2-4}$

As the statement says, the proposed use of thromboplastin reference preparations is for the characterization of national reference preparations and not for use as working reference reagents in hospitals. The only snag is that to date there is only one national reference reagent-that is, the British Comparative Thromboplastin, and the character of this is far better established than that of any of the reference preparations. Its quality control at the production centre: at the expert monitoring laboratories, and via the independent assessor is far stricter than any other thromboplastin. If therefore these reference preparations are to be of clinical value there must be development of national systems of anticoagulant control, perhaps similar to the British system, in order to provide working reference reagents for individual hospitals and for commercial manufacturers.-I am, etc.,

National Thromboplastin Centre,

L. Poller Haematology Department

Wanchester
Manthing

1 Biggs, R., anl Denson, K. W. E., British Medical Fourna!, 1967, 1, 84.

Poller, L., Association of Clinical Pathologists
Broadsheet, 1970, No.71. Poller, L., British foumal of Haematology, 1971 20. 359.

- Thomson, Jean M., A Practical Guide to Blood Coagulation and Haemostasis, p. 172. Churchill,
London, 1970. 